\title{
Phytanic acid activates NADPH oxidase through transactivation of epidermal growth factor receptor in vascular smooth muscle cells
}

Gursev S. Dhaunsi ${ }^{1^{*}}$, Mayra Alsaeid ${ }^{1}$ and Saghir Akhtar ${ }^{2}$

\begin{abstract}
Background: Phytanic acid (PA) has been implicated in development of cancer and its defective metabolism is known to cause life-threatening conditions, such as Refsum disease, in children. To explore molecular mechanisms of phytanic acid-induced cellular pathology, we investigated its effect on NADPH oxidase (NOX) and epidermal growth factor receptor (EGFR) in rat aortic smooth muscle cells (RASMC).

Methods: Smooth muscle cells were isolated from rat aortae using enzymic digestion with collagenase and elastase. Cultured RASMC were treated with varying concentrations $(0.5-10 \mu \mathrm{g} / \mathrm{ml})$ of phytanic acid in the presence/absence of fetal bovine serum (FBS) and/or EGFR inhibitor, AG1478. Following treatment with experimental agents, NOX activity was assayed in RASMC cultures by luminescence method. Gene expression of NOX-1 and p47phox was assessed using RT-PCR. NOX-1, p47phox and, total EGFR protein and its phosphorylated form were measured by Western blotting.

Results: Treatment of RASMC with supraphysiological concentrations $(>2.5 \mu \mathrm{g} / \mathrm{ml})$ of PA significantly $(p<0.01)$ increased the NOX activity. PA also significantly increased gene/protein expression of NOX-1 and p47phox whereas p22phox and p67phox remained unaffected. Interestingly, PA $(2.5-10 \mu \mathrm{g} / \mathrm{ml})$ markedly $(2-3$ folds) increased the total and phosphorylated EGFR. Treatment of cells with EGFR inhibitor, AG1478, significantly blocked the PA-induced enhancement of NOX activity.

Conclusions: Our findings that PA transactivates EGFR and induces NOX activity in vascular smooth muscle cells provide new insights into molecular mechanisms of PA's role in cancer and Refsum disease.
\end{abstract}

Keywords: Phytanic acid, Aortic smooth muscle, NADPH oxidase, EGFR

\section{Background}

Phytanic acid (PA) is a branched fatty acid that is synthesized from phytol during degradation of plant chlorophyll and catabolized in mammalian cells through peroxisome enzyme system [1, 2]. Major amount of circulating phytanic acid in humans comes from dietary sources such as meats and dairy products [3]. PA metabolism was recognized to be vital for human health with the identification of peroxisomal disorders, such as

\footnotetext{
* Correspondence: dhaunsig@hsc.edu.kw

${ }^{1}$ Departments of Pediatrics, Faculty of Medicine, Kuwait University, Kuwait City, Kuwait

Full list of author information is available at the end of the article
}

Zellweger syndrome and Refsum disease where supraphysiological amounts of phytanic acid were found to accumulate in body tissues and fluids of the patients [4-6]. Peroxisomal disorder patients with aberrant phytanic acid metabolism often experience severe clinical complications that range neurological impairment to cardiovascular anomalies [7, 8]. PA has been reported to inhibit $\mathrm{Na}^{+}, \mathrm{K}^{+}$-ATPase activity and mitochondrial respiratory chain complex (s) possibly causing impairment of synaptic function $[9,10]$. A number of nuclear transcription factors called peroxisome proliferator-activated receptors (PPAR), particularly PPAR- $\alpha$, have strong affinity for PA and their 
activation through ligand binding affects lipid metabolism, besides other responses [11]. Idel and coworkers [12] have reported that supraphysiological levels of phytanic acid induce nitric oxide-mediated apoptosis in cultured vascular smooth muscle cells suggesting thereby that phytanic acid might have a role in regulation of cell growth in vivo. Though nitric oxide has recently been implicated in phytanic acid-induced apoptosis of smooth muscle cells, any role of reactive oxygen species such as highly reactive superoxide anion production in relation to phytanic acid-mediated regulation of vascular growth remains to be examined. NADPH oxidase (NOX), a multicomponent enzyme system, is a major source of superoxide anion formation in various tissues including vascular smooth muscle cells $[13,14]$. Though originally reported for its presence in phagocytes, NOX is now known to be expressed in all vascular cell types and participates in various physiological functions such as regulation of vascular tone and pathological conditions such as diabetes, hypertension and atherosclerosis [15-17]. In vascular smooth muscle cells, NOX activity is regulated by a catalytic unit NOX-1 and several subunits such as p22phox, p47phox, p67phox and rac-1, and one or more than one of these components of NOX have been reported to be modulated during different pathological conditions $[18,19]$. Though NOX system has been extensively investigated and reported for its modulation by various vasoactive molecules such as angiotensin-II, PDGF and cytokines [20-22], it has remained unclear if phytanic acid, a biomolecule linked with severe cellular pathology in peroxisomal disease, has any influence on superoxide anion production by NOX.

Recently, increased serum levels of PA have been linked to development of several types of cancers that include prostate, breast and colon [23], however molecular mechanism (s) of PA-induced cellular pathology in carcinogenesis remain unknown. Overproduction of reactive oxygen species (ROS) has been reported as one of the several culprits for development of cancer in humans and NOX-mediated generation of ROS is known to contribute towards formation of tumors [24, 25]. EGFR, a cell surface receptor with intrinsic protein kinase activity, has been recognized as a key player in vascular biology and, development and progression of cancer due to its diverse signaling responses to regulate cellular proliferation, differentiation, migration and survival $[26,27]$. EGFR mutations and overexpression have been widely linked to various types of cancers, leading the way to development of EGFR inhibitors as anticancer agents [28]. PA-mediated risk of cancer has attracted the attention of several research groups, yet any role of EGFR, a key cell growth regulator, in PA-induced cellular pathology has remained unexplored. This study was carried out to investigate the effect of PA on NOX and EGFR in vascular smooth muscle cells, to understand cellular and molecular mechanisms of PA-induced pathogenesis in peroxisomal disorders and development of cancer. Vascular smooth muscle cells have been used in previous studies to examine PA-induced pathogenic effects. Vascular smooth muscles were employed as an experimental model in this study due to their well reported active participation in lipid metabolism and their role in growth factors-/receptors- and NOX-mediated pathogenesis in proliferative vascular diseases.

\section{Methods}

Male Wistar Rats (weighing 100-125 g) were used in this study according to the United States National Institute of Health (NIH) guidelines for the Care and Use of Laboratory Animals (NIH Publication No. 85-23, revised in 1996). The study protocols (MK01/12) were approved by the Research Ethics Committee of Health Sciences Center, Kuwait University.

\section{Materials}

Bovine serum albumin (BSA), penicillin/streptomycin and fetal bovine serum (FBS) were purchased from Sigma Chemical Company (St. Louis, MO). DMEMHam's F-12 (1:1) and trypsin-EDTA were from GIBCO (Grand Island, NY). Lucigenin, NADPH and phytanic acid were purchased from Sigma Chemical Co. Primaria tissue culture plates were obtained from Falcon Becton Dickinson (Oxnard, CA). All other reagents were of highest quality available and purchased from Sigma or Calbiochem.

\section{Methods}

\section{Aortic smooth muscle cell cultures}

Rats were anesthetized with metofane and sacrificed by ventricular puncture for the removal of thoracic aortae. Aortic smooth muscle cells were cultured using enzymic digestion of aortic tissue by collagenase and elastase as described earlier [29]. Thoracic aortas were cleaned of the adherent fatty tissue and washed with sterile Hank's medium. Aortas were then incubated for $20 \mathrm{~min}$ at $37^{\circ} \mathrm{C}$ in the digestion mixture that contained $1.5 \mathrm{mg} / \mathrm{ml} \mathrm{BSA}$, $25 \mathrm{U} / \mathrm{ml}$ of pancreatic Elastase (Sigma, USA) and 200U/ml Collagenase (type IX, Sigma, USA). After the incubation period, adventitia was removed and, the medial layer was cut into small fragments and digested by incubation in digestion mixture for another $45 \mathrm{~min}$ followed by washing twice with fresh DMEM and centrifugation. Isolated cells were suspended in DMEM-F12 HAM containing $10 \%$ heat-inactivated fetal bovine serum and plated onto $25-\mathrm{cm}^{2}$ culture flasks for culture in humidified conditions under $5 \% \mathrm{CO}_{2}$. The obtained RASMC 
were characterized by immunostaining with monoclonal antibody specific for smooth muscle $\alpha$-actin.

\section{Treatment of cell cultures}

Aortic smooth muscle cells grown in culture plates were used in all experiments. Before adding the experimental agents, cell monolayers were washed twice with serum free DMEM-F/12 medium (SFM) and incubated at $37{ }^{\circ} \mathrm{C}$ in a humidified cell culture incubator for $2 \mathrm{~h}$ in the presence of $0.1 \%$ FBS containing DMEM-F/12 medium. Phytanic acid $(0-10 \mu \mathrm{g} / \mathrm{ml})$ was mixed with $\alpha$ cyclodextrin-containing DMSO $(0.001 \% \mathrm{v} / \mathrm{v})$ and added to the cell cultures in the presence or absence of FBS (5\%) and/or $50 \mu \mathrm{M}$ of AG1478. Following the addition of experimental agents, cells were incubated in cell culture incubator for another $20-24 \mathrm{~h}$ at $37^{\circ} \mathrm{C}$.

\section{Assay of NADPH oxidase activity}

NADPH oxidase activity was measured in cell homogenates at $37{ }^{\circ} \mathrm{C}$ using lucigenin and NADPH as described elsewhere [30]. Briefly, NOX activity was measured in cell homogenates in a reaction mixture that contained $50 \mathrm{mM}$ phosphate buffer, $\mathrm{pH}$ 7.1, $0.01 \mathrm{mM}$ EDTA and $25 \mu \mathrm{M}$ lucigenin. Reaction was started by addition of $100 \mu \mathrm{M}$ of NADPH and chemluminiscence was recorded over a period of $3 \mathrm{~min}$. Specific enzyme activity was calculated as relative light units (RLU) emitted per sec per mg of protein.

\section{RNA isolation and reverse transcription}

In each experiment, total RNA was extracted from cultured smooth muscle cells with RNA extraction kit based on use of guanidinium thiocyanate, lithium chloride and cesium triflouroacetate. Isolated RNA was of high quality and was used immediately for synthesis of first strand cDNA according to protocols from Clonetech's SMART PCR cDNA synthesis kit.

\section{PCR detection of mRNA for NOX-1, p22phox, p47phox, p67phox and G3PDH}

Amplification of cDNA obtained from reverse transcription of RNAs from RASMCs was carried out using Advantage cDNA PCR kit (BD Biosciences Clonetech) and the following primers: NOX-1; 5' -GCC AGA CTC AGA GTT GGA GAT GCT-3' and 5'-GCA GTT TCA AGA TGC GTG GAA ACT A-3', p22phox; 5'-GTA GAT GCC GCT CGC AAT GGC CAG-3' and 5' - ATG GGG CAG ATC GAG TGG GCC ATG T-3', p47phox; 5'CTT TGG GCA TCA AGT ATG TCT C-3' and $5^{\prime}$-ATC AAT CCA GAG AAC AGG ATC A-3' and p67phox; 5'TGC CTT TTC CAG TAC TAC CTA TGT C-3' and 5'-CTC TCA TCT GAC ACT CCC ATT TAA C-3'. Primers for G3PDH were provided by Clonetech. First strand of cDNA obtained from reverse transcription was denatured for $1 \mathrm{~min}$ at $95{ }^{\circ} \mathrm{C}$ and subjected to PCR with following parameters; $95{ }^{\circ} \mathrm{C}$ for $30 \mathrm{sec}, 58{ }^{\circ} \mathrm{C}$ or $62{ }^{\circ} \mathrm{C}$ for $30 \mathrm{sec}, 68^{\circ} \mathrm{C}$ for $45 \mathrm{sec}, 25-30$ cycles after denaturing at $95{ }^{\circ} \mathrm{C}$ for $1 \mathrm{~min}$. PCR products for various NOX components were analyzed using $2 \%$ agarose gel electrophoresis.

\section{Western blot analysis of NOX-1, p47 phox and EGFR} Western blotting for NOX-1, p47 phox and total or phosphorylated forms of EGFR was performed as described earlier [31]. Briefly, cell pellets were transferred to lysis buffer ( $\mathrm{pH}$ 7.6) containing $50 \mathrm{mM}$ Tris-base, $5 \mathrm{mM}$ EGTA, $150 \mathrm{mM} \mathrm{NaCl}, 1 \%$ Triton 100, $2 \mathrm{mM}$ $\mathrm{Na}_{3} \mathrm{VO}_{4}, 50 \mathrm{mM}$ NAF, $1 \mathrm{mM}$ PMSF, $20 \mu \mathrm{M}$ phenylarsine, $10 \mathrm{mM}$ sodium molybdate, $10 \mu \mathrm{g} / \mathrm{ml}$ leupeptin and $8 \mu \mathrm{g} / \mathrm{ml}$ aprotinin). Aliquots containing equal amounts of protein were subjected to SDS-PAGE gel electrophoresis (SDS-PAGE) and transferred onto nitrocellulose membrane. Monoclonal antibodies were used to detect NOX-1, p47 phox and, phosphorylated and total forms of EGFR. Secondary antibodies conjugated to horseradish peroxidase were employed to get immunoreactive bands that were detected with Super Signal chemiluminescent substrate. Images were finally analyzed and quantified by densitometry and all data normalized to $\beta$-actin levels.

\section{Data analysis}

Values shown in the results are mean \pm standard deviation of four experiments carried out in triplicate. Student's $t$ test was employed using SPSS software to determine statistical significance of the results.

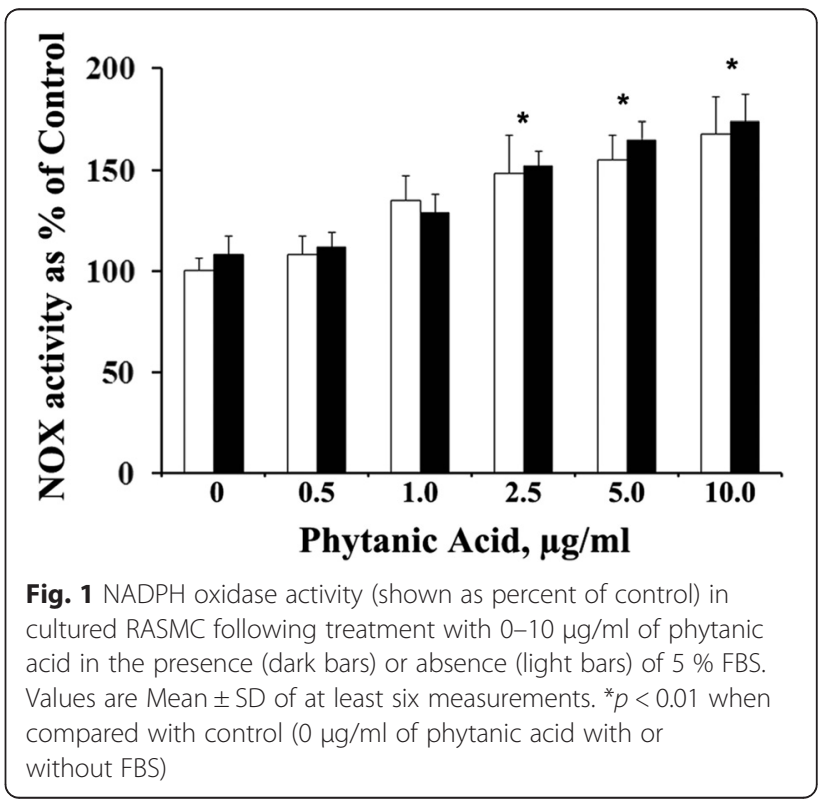




\section{Results}

\section{Effect of Phytanic acid on NOX in RASMC cultures}

Figure 1 shows that $24 \mathrm{~h}$ treatment of RASMC with supra-physiological concentrations $(2.5-10 \mu \mathrm{g} / \mathrm{ml})$ of phytanic acid significantly $(p<0.01)$ increased the NOX activity irrespective of the presence or absence of FBS in the culture medium. In relation to the observed activation of NOX activity by phytanic acid, we examined the gene/protein expression and of various NOX components in RASMC cultures treated with phytanic acid in the presence or absence of FBS. Figure 2 shows the results of PCR analysis of NOX-1, the catalytic unit of NOX and sub-component p47phox in smooth muscle cells following treatment with PA and or FBS. PCR analysis illustrated in Fig. $2 \mathrm{~b}$ shows that the ratios of the levels of NOX-1 or p47phox gene transcripts and GAPDH were significantly increased $(p<0.01)$ in RASMC treated with phytanic acid $(5 \mu \mathrm{g} / \mathrm{ml})$ in the presence or absence of $5 \%$ FBS. Stimulation of cells with FBS-alone did not have any significant effect on the gene transcripts of NOX-1, however p47phox was significantly $(p<0.01)$ elevated. Protein levels of NOX-1 as well as p47phox were markedly increased following treatment of RASMC with phytanic acid in the presence or absence of FBS (Fig. 3). Phytanic acid treatment, however did not have any significant effect on gene expression of p22phox or p67phox in RASMC cultures (data not shown).

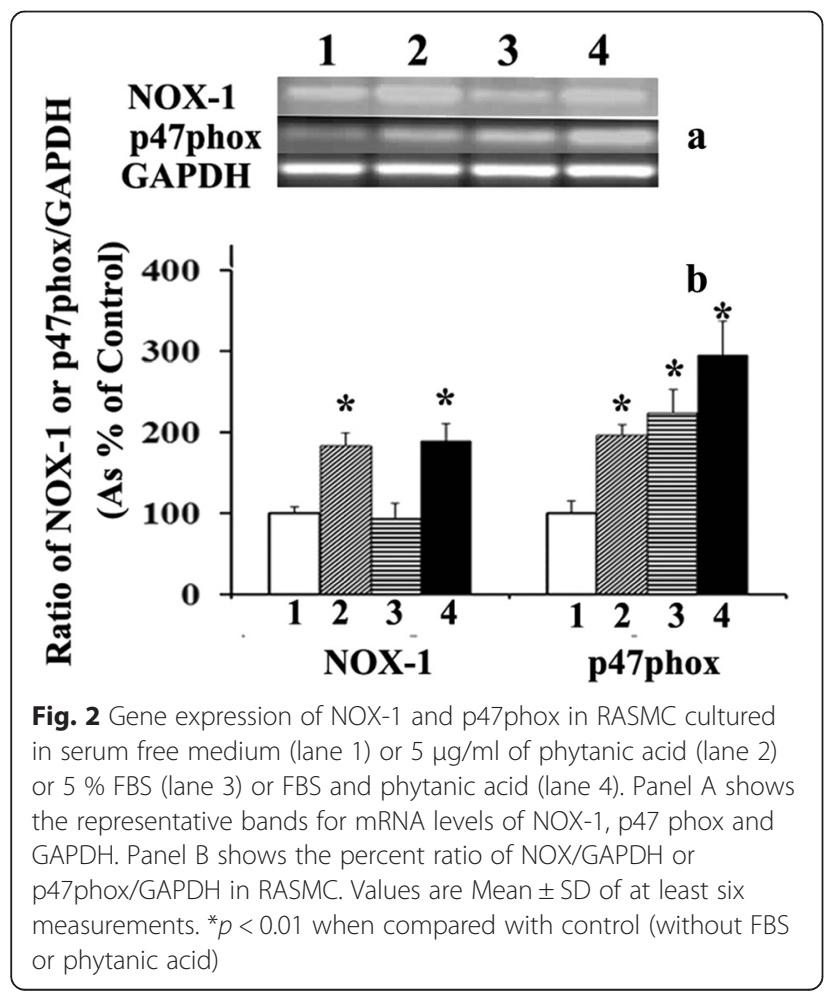

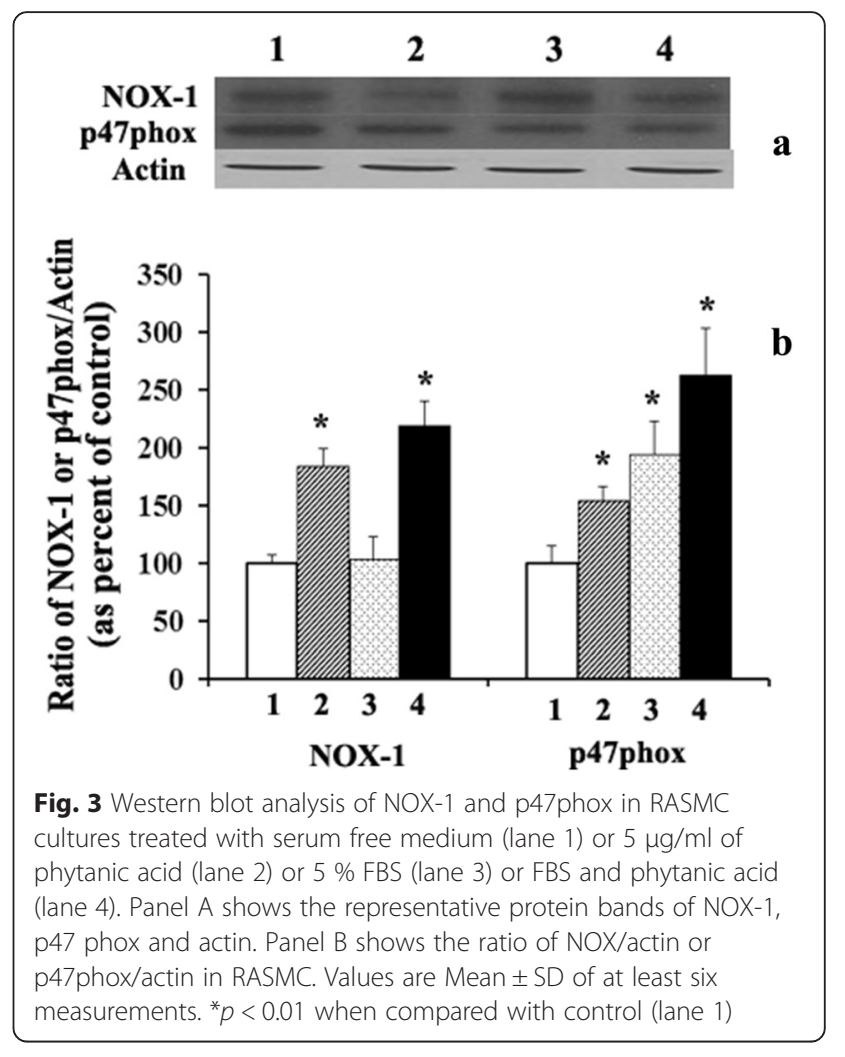

\section{Effect of phytanic acid on EGFR}

Figure 4 shows that treatment of RASMC with supraphysiological concentrations $(2.5-10 \mu \mathrm{g} / \mathrm{ml})$ of phytanic acid significantly $(p<0.01)$ increased the expression of total EGFR protein in the presence or absence of FBS. Phytanic acid also significantly $(p<0.01)$ enhanced the phosphorylation of EGFR, however the effect was more pronounced in cells treated with $10 \mu \mathrm{g} / \mathrm{ml}$ of PA in the presence of FBS.

\section{Effect of AG1478 on PA-induced NOX activity}

EGFR specific inhibitor, AG1478, significantly $(p<0.01)$ blocked the PA-induced NOX activity as shown in Fig. 5. FBS did not have any significant effect on NOX activity in the presence or absence of PA and/or AG1478.

\section{Discussion}

A marked increase in the levels of phytanic acid in body tissues and fluids of patients with Refsum disease and Zellweger syndrome has, for many years, implicated this branched fatty acid in development and progression of the disease $[4,5]$, yet the underlying molecular mechanisms of such a role for PA in pathogenesis of peroxisomal diseases have remained elusive. More recently, increased levels of PA have been linked with an increased risk of developing cancer [25], however pathogenic mechanisms have remained unidentified. This 

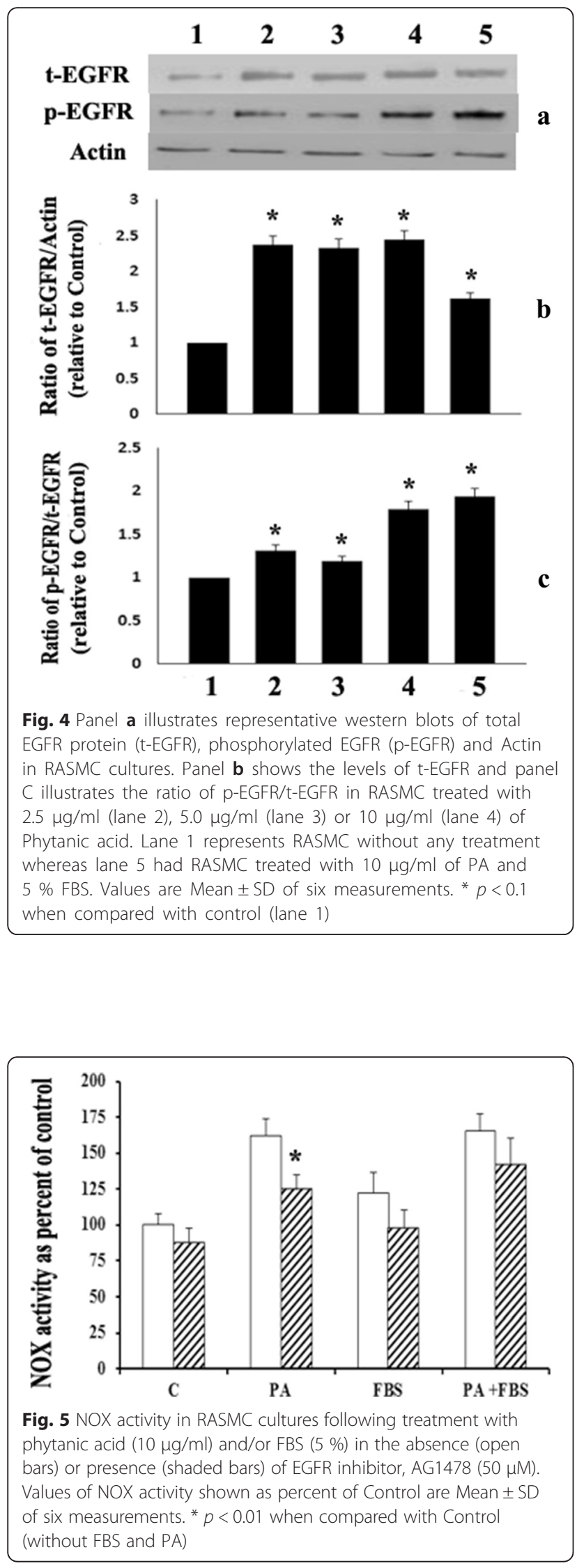

study provides some new insights into molecular mechanisms of PA-mediated cellular pathology.

Besides several other mechanisms suggested for the regulation of cellular functions by different fatty acids, intracellular production of or exposure to extracellular cytokines, reactive oxygen species and nitric oxide production have been reported to mediate fatty acid-induced effects on cell survival [32,33]. The supraphysiological concentrations of phytanic acid have been shown earlier to enhance nitric oxide production in vascular smooth muscle cells and induce apoptosis [12]. Nitric oxide is an important regulator of vascular biology and has been widely reported to inhibit vascular growth in vivo as well as in cell culture studies [34]. Nitric oxide-mediated effects have been reported to be influenced by the superoxide anion production, as these two species interact to generate a highly reactive peroxynitrite molecule [35]. Our findings that PA activates NOX activity through upregulation of NOX-1 and p47phox proteins, strongly suggests that nitric oxide may not be the only reactive nitrogen/ oxygen species formed in response to phytanic acid, superoxide formation as a result of NOX activation, may well be a key ROS produced in response to PA that may further lead to formation of highly reactive peroxynitrite. ROS, such as superoxide radicals and hydrogen peroxide have been reported earlier to modulate the proliferation of smooth muscle cells in vivo as well as in vitro studies [36]. Enzymatic activity of NOX has been well reported to be regulated through interaction of its various components, p22phox, p47phox and p67phox. Our findings that phytanic acid enhances NOX-1 and p47phox levels through transcriptional and translational activation without having any significant effect on expression of p22 phox and p67phox proteins indicate that this branched fatty acid possibly plays a role in regulation of cellular oxidative stress through activation of NOX and thus provides a novel molecular mechanism for the actions of phytanic acid in conditions of peroxisomal dysfunction or carcinogenesis. Our finding that PA-induced enhancement of NOX activity is partly blocked by AG1478, an EGFR inhibitor, unravels the involvement of EGFR, another key cell growth regulator, in PA-mediated pathogenic events. Over expression of EGFR is associated with cancer development. The fact that PA increased the expression of EGFR protein and enhanced its phosphorylation strongly indicates that the reported carcinogenic capability of PA in various types of cancers is likely occurring through activation of EGFR tyrosine kinase.

Impairment of the PA-induced NOX activity by EGFR inhibitor strongly suggests that induction of EGFR gene expression and phosphorylation of EGFR precede the activation of NOX activity in response to ex vivo treatment of RASMC with PA. Future in vivo studies might provide physiological importance of our findings however, 
this ex vivo study on RASMC cultures establishes an important link between PA-induced transactivation of EGFR and formation of NOX-mediated ROS production providing a possible molecular mechanism of cellular pathology of peroxisomal dysfunction in cases of Refsum disease and PA-related carcinogenesis.

\section{Conclusions}

This ex vivo study carried out on vascular smooth muscle cells concludes that PA increases NOX activity through transcriptional activation of NOX-1 and p47phox. An increase in phosphorylation of EGFR by PA and attenuation of PA-induced NOX activity by EGFR inhibitor provide an important insight into molecular mechanism of PA's role in pathogenesis of some peroxisomal diseases and cancers.

\section{Acknowledgement}

Authors would like to thank Mrs. Nini Mathews, Mrs. Bindu Chandrasekhar and Ms. Heba Dalvi for their technical assistance. This study was supported by a research grant MK 01/12 from Research Sector, Kuwait University.

\section{Authors' contributions}

GD: Planned the study, carried out experiments, analyzed data and prepared the rough draft of manuscript. MA: Helped plan the study. Analyzed data and participated in preparing final manuscript. SA: Conducted experiments on EGFR, analyzed data and edited the manuscript. All authors read and approved the final manuscript.

\section{Competing interests}

The authors declare that they have no competing interests.

\section{Author details}

'Departments of Pediatrics, Faculty of Medicine, Kuwait University, Kuwait City, Kuwait. ${ }^{2}$ Pharmacology and Toxicology, Faculty of Medicine, Kuwait University, Kuwait City, Kuwait.

\section{Received: 29 December 2015 Accepted: 7 June 2016}

Published online: 10 June 2016

\section{References}

1. Van den Brink DM, Wanders RJ. Phytanic acid: production from phytol, its breakdown and role in human disease. Cell Mol Life Sci. 2006;63:1752-65.

2. Wanders RJ, Komen J, Ferdinandusse S. Phytanic acid metabolism in health and disease. Biochim Biophys Acta. 1811;2011:498-507.

3. Hellgren LI. Phytanic acid-an overlooked fatty acid in dairy fat? Ann N Y Acad Sci. 2010;1190:42-9.

4. Wierzbicki AS. Peroxisomal disorders affecting phytanic acid alph-oxidation: a review. Biochem Soc Trans. 2007:35:881-6.

5. Van Veldhoven PP. Biochemistry and genetics of inherited disorders of peroxisomal fatty acid metabolism. J Lipid Res. 2010;51:2863-95.

6. Krause C, Rosewich H, Gartner J. Rational diagnostic strategy for Zellweger syndrome spectrum patients. Eur J Hum Genet. 2009:17:741-8.

7. Wierzbicki AS. Clinical significance of oxidation from phytol to phytanic acid in man. Mol Genet Metab. 2004:83:347.

8. Wanders RJ, Jansen GA, Skjeldal OH. Refsum disease, peroxisomes and phytanic acid oxidation: a review. J Neuropathol Exp Neurol. 2001;60:1021-31.

9. Schonfeld P, Wojtczak L. Fatty acids decrease mitochondrial generation of reactive oxygen species at the reverse electron transport but increase it at the forward transport. Biochim Biophys Acta. 2007;1767:1032-40.

10. Busanello EN, Zanatta A, Tonin AM, Viegas CM, Vargas CR, Leipnitz G, Ribeiro CA, Wajner M. Marked inhibition of $\mathrm{Na}+, \mathrm{K}(+)$-ATPase activity and the respiratory chain by phytanic acid in cerebellum from young rats: possible underlying mechanisms of cerebellar ataxia in Refsum disease. J Bioenerg Biomembr. 2013;45:137-44.

11. Grygiel_Gorniak B. Peroxisome proliferator-activated receptors and their ligands: nutritional and clinical implications-a review. Nutr J. 2014;13:17.
12. Idel S, Ellinghaus P, Wolfrum C, Nofer JR, Gloerich J, Assmann G, Spener F, Seedorf $U$. Branched chain fatty acids induce nitric oxide-dependent apoptosis in vascular smooth muscle cells. J Biol Chem. 2002;277:49319-25.

13. Van Heerebeek L, Meischi C, Stooker W, Meijer CJ, Niessen HW, Ross D. NADPH oxidase (s): new source (s) of reactive oxygen species in the vascular system. J Clin Pathol. 2002;55:561-8.

14. Bengtsson SH, Gulluyan LM, Dusting GJ, Drummond GR. Novel isoforms of NADPH oxidase in vascular physiology and pathophysiology. Clin Exp Pharmacol Physiol. 2003;30:860-6.

15. Guichard C, Moreau R, Pessayre D, Epperson TK, Krause KH. NOX family NADPH oxidases in liver and in pancreatic islets: a role in the metabolic syndrome and diabetes? Biochem Soc Trans. 2008;36:920-9.

16. Sedeek M, Hebert RL, Kennedy CR, Burns KD, Touyz RM. Molecular mechanisms of hypertension: role of Nox family NADPH oxidases. Curr Opin Nephrol Hyperten. 2009;18:122-7.

17. Violi F, Basili S, Nigro C, Pignatelli P. Role of NADPH oxidase in atherosclerosis. Future Cardiol. 2009:5:83-92.

18. Barry-Lane PA, Patterson C, van der Merwe M, Hu Z, Holland SM, Yeh ET, Runge MS. p47phox is required for atherosclerotic lesion progression in ApoE (-/-) mice. J Clin Invest. 2001;108:1513-22.

19. Weaver M, Liu J, Pimentel D, Reddy DJ, Harding P, Peterson EL, Pagano PJ. Adventitial delivery of dominant-negative p67phox attenuates neointimal hyperplasia of the rat carotic artery. Am J Physiol Heart Circ Physiol. 2006; 290:H1933-41.

20. Herrera M, Silva GB, Garvin JL. Angiotensin II stimulates thicj ascending limb superoxide production via protein kinase $\mathrm{c}(\mathrm{a})$-dependent NADPH oxidase activation. J Biol Chem. 2010;285:21323-8.

21. Morgan MJ, Liu ZG. Reactive oxygen species in TNF alpha-induced signaling and cell death. Mol Cells. 2010;30:1-12.

22. Kreuzer J, Viedt $C$, Brandes RP, Seeger F, Rosemkranzz AS, Sauer H, Babich A, Nurnberg B, Kather H, Krieger-Brauer HI. Platelet-derived growth factor activates production of reactive oxygen species by NAD (P) H oxidase in smooth muscle cells through Gi1,2. FASEB J. 2003;17:38-40.

23. Lloyd MD, Darley DJ, Wierzbicki AS, Threadgill MD. Alpha-methylacyl-CoA racemase.an "obscure' metabolic enzyme takes center stage. FEBS J. 2008; 275:1089-102.

24. Roy K, Wu Y, Meitzler JL, Juhasz A, Liu H, Jiang G, Lu J, Antony S, Doroshow JH. NADPH oxidases and cancer. Clin Sci. 2015;128:863-75.

25. Helfinger V, Henke N, Harenkamp S, Walter M, Epah J, Penski C, Mittelbron M, Schroder K. The NADPH Oxidase Nox4 mediated tumor angiogenesis. Acta Physiol. 2016;216:435-46.

26. Appert-Colin A, Hubert P, Cremel G, Bennasroune A. Role of ErbB receptors in cancer Cell Migration and Invasion. Frontiers Pharmacol. 2015;6:1-10.

27. Schreier B, Gekle M, Grossman C. Role of epidermal growth factor receptor in vascular structure and function. Curr Opin Nephrol Hypertens. 2014;23:113-21.

28. Kota R, Gundet S, Gullipalli M, Linga VG, Maddali LS, Digumarti R. Prevalence and outcome of epidermal growth factor mutations in non-squamous nonsmall cell lung cancer patients. Lung India. 2015;32:561-5.

29. Dhaunsi GS, Hassid A. Atrial and C-type natriuretic peptides amplify growth factor activity in primary aortic smooth muscle cells. Cardiovasc Res. 1996:31:37-47.

30. Jalil JE, Perez A, Ocaranza MP, Bargetto J, Galaz A, Lavandero S. Increased aortic NADPH oxidase activity in rats with genetically high angiotensinconverting enzyme levels. Hypertension. 2005;46:1362-7.

31. Akhtar S, Yousif MH, Chandrasekhar B, Benter IF. Activation of EGFR/ERBB2 via pathways involving ERK1/2, P38 MAPK, AKT and FOXO enhances recovery of diabetic hearts from ischemia-reperfusion injury. PLoS One. 2012;7(6), e39066

32. Hirafuji M, Machida T, Tsunida M, Miyamoto A, Minami I. Docosahexaenoic acid potentiates interleukin-1 beta induction of nitric oxide synthase through mechanism involving p44/42 MAPK activation in rat vascular smooth muscle cells. Br J Pharmacol. 2002;136:613-9.

33. Naseem KM. The role of nitric oxide in cardiovascular diseases. Mol Aspects Med. 2005:26:33-65

34. Bian K, Doursout MF, Murad F. Vascular system: role of nitric oxide in cardiovascular diseases. J Clin Hypertens. 2008;10:304-10.

35. Ginnan R, Guikema BJ, Halligan KE, Singer HA, Jourd'heuil D. Regulation of smooth muscle by inducible nitric oxide synthase and NADPH oxidase in vascular proliferative diseases. Free Radic Biol Med. 2008;44:1232-45.

36. Nickenig G, Baudler S, Muller C, Werner C, Werner N, Welzel H, Strehlow K, Bohm M. Redox-sensitive vascular smooth muscle cell proliferation is mediated by GKLF and Id3 in vitro and in vivo. FASEB J. 2002;16:1077-86. 